\title{
Identity, politics, and the pandemic: Why is COVID-19 a disaster for feminism(s)?
}

\author{
Suze G. Berkhout ${ }^{1,2}$ (D) Lisa Richardson ${ }^{1,3}$
}

Received: 26 August 2020 / Accepted: 3 October 2020 / Published online: 13 October 2020

(C) Springer Nature Switzerland AG 2020

\begin{abstract}
COVID-19 has been called "a disaster for feminism" (Lewis in The coronavirus is a disaster for feminism, 2020) for numerous reasons. In this short piece, we make sense of this claim, drawing on intersectional feminism(s) to understand why an analysis that considers gender alone is inadequate to address both the risks and consequences of COVID-19.
\end{abstract}

Keywords Intersectionality $\cdot$ Feminism $\cdot$ COVID-19 pandemic

\section{Introduction}

Calls to track disproportionate risks and consequences of the Coronavirus Disease 2019 (COVID-19) pandemic for women have come from a range of sectors. Globally, limited gains in gender equality since the 1995 Beijing Platform for Action have been flagged as at risk of being rolled back as the pandemic deepens preexisting inequalities (United Nations Policy Brief, April 2020). Early in the pandemic, Nature published a commentary discussing how social restrictions impact women especially, given that they are disproportionately responsible for family care work and also make up the majority of single parents (Minello 2020). Unpaid care responsibilities have increased dramatically as COVID-19 has closed schools, overwhelmed health services, and heightened the care needs of older persons-these

Suze G. Berkhout

suze.berkhout@uhn.ca

1 University Health Network, Toronto General Hospital, 8th floor Eaton North, 228A, 200

Elizabeth St., Toronto, ON M5G 2C4, Canada

2 Department of Psychiatry, University of Toronto, Toronto, Canada

3 Department of Medicine, University of Toronto, Toronto, Canada 
have both disproportionately burdened women and exposed the fragility of women's roles in the paid economy (Power 2020). In the popular press, COVID-19 has been called "a disaster for feminism" (Lewis 2020) as heightened care obligations within the pandemic context negatively impact many women's financial and employment security. In this short piece, we make sense of how COVID-19 has been considered a disaster or crisis for feminism(s) and why an analysis that considers gender alone is inadequate to address the issues. ${ }^{1}$

In answering this question, it is crucial to emphasize "women" are not a uniform demographic group. Feminist discourses surrounding the pandemic that fail to locate intersections of racism, patriarchy, ableism and heteronormativity (amongst other axes of social power) will be inadequate for understanding and addressing vulnerability: an intersectional analysis is needed along with a response that centres the experiences of multiply positioned community members. We bring to this analysis our own positionalities: Suze Berkhout is an urban, white, ${ }^{2}$ settler woman; she is a clinician-investigator in feminist science and technology studies (STS) and philosophy whose research is embedded in ethnographic methodologies and she is a practicing psychiatrist. Lisa Richardson is a mixed Anishinaabe Kwe who is a clinician-educator and education researcher with a focus on the integration of critical, Indigenous and feminist perspectives in medical education; she practices as a general internist and leads numerous Indigenous health initiatives at the local and national level. As physicians as well as researchers, each of us brings our understandings of intersectionality to our clinical and academic work.

Intersectionality refers to the multiple ways in which oppressive systems overlap: injustices are based not only on gender, but on race, ethnicity, sexuality, economic background, (dis)ability, geography, and religion, as well as other sources of discrimination and subordination. An intersectional analysis offers a way of thinking about how such systems intersect and interact, impacting individuals who are differently positioned with respect to their social identities (Cho et al. 2013). With origins in critical race theory and Black feminist scholarship, intersectionality was developed as an alternative to forms of identity politics that ignore or conflate intra group differences (Crenshaw 1991); it focuses instead on the shifting webs of relationships that our identities are tied to (Woods 2012). Taken up within social justice discourses in a range of scholarly fields, intersectionality is also a critical praxis as much as an analytic strategy. What do intersectional approaches to the pandemic reveal?

\footnotetext{
1 This note belongs to the Topical Collection "Seeing Clearly Through COVID-19: Current and future questions for the history and philosophy of the life sciences", edited by G. Boniolo and L. Onaga.

${ }^{2}$ We capitalize Black but not white when referring to racial group terms, following the explanation offered by the Columbia Journalism Review—that while Black reflects (for many) a shared set of experiences in relation to identity (just as Indigenous includes myriad groups united by shared experiences under colonialism), in the current context, capitalizing the "W" in white carries a set of meanings that risks following the lead of white supremacist groups. And while we recognize that the lack of capitalization of white has been taken by some to imply that whiteness is somehow outside of race, we have weighed this against the larger context in which white is capitalized. See Laws 2020.
} 


\section{Elevated risks of infection: COVID is not a "great equalizer"}

Early in the pandemic, the notion that COVID-19 was a "great equalizer" was frequently touted. This view, that risks from the virus could impact anyone regardless of their positionality, has been roundly criticized as the pandemic amplifies existing health inequality (Mein 2020). An intersectional feminist analysis helps to understand how disproportionate risks are materialized as lived reality.

Elevated infection and fatality rates have devastated long term care settings across North America and Europe. These settings have been flagged as a gender crisis: women are two-thirds of residents and more than $90 \%$ of paid staff (Estabrooks and Keefe 2020). But it is often women racialized as minorities who are engaged in frontline care work, particularly in positions structured by parttime contracts leading to jobs across multiple sites and roles with high exposure and patient contact. In general, long term care settings have had less access to personal protective equipment compared to hospitals, contributing to higher rates of infection amongst staff and residents. Many westernized health care systems have emphasized acute services while deprioritizing community care. But it is notable that safety standards decrease along with pay scales when a workforce is racialized and feminized (Das Gupta 2006). And although workplace safety rights are guaranteed through law, non-professionalized care workers are often less able to assert those rights. Black, Indigenous, Latinx, and Southeast Asian women in these workplaces are also more likely to be caregivers for multigenerational kin or to send financial support to family abroad. They are more likely to depend on their work for subsistence survival. These factors limit their ability to refuse unsafe work (Lopez 2018). Intersections of race, gender, economic position, and migration overlap to heighten risks for particular women especially, within a larger context of funding priorities.

Prison settings have also experienced notably higher infection rates. An intersectional analysis asks us to consider gender in relation to race, economic background, migration status, and disability, amongst other identities. Certainly, COVID-19 exposure in prisons overwhelmingly impacts men racialized as minorities (Black men especially), who bear the brunt of police attention, are more likely to receive stiffer judicial penalties, and less likely to access plea bargaining than white men with comparable offenses (Nellis 2016). But when we consider gender in relation to other axes of social oppression, it is also clear that in Canada and in the United States, for instance, Indigenous, Black, and Latinx women are incarcerated at disproportionate rates, even as the white female prison population has grown (Kajstura 2019). Undiagnosed as well as untreated learning disorders, mental health challenges, and physical health concerns are prevalent for racialized women in prison settings (Annamma 2018); incarcerated women are much more likely to have had prior mental health hospitalizations and women prisoners have disproportionately experienced past and current abuse compared to both the general community and wider prison populations. We see greater intersections of identity-related vulnerability for women within this context, but such dynamics often remain hidden from public scrutiny. An intersectional analysis offers us a 
way to understand important aspects of risk for both men and women in carceral settings, including where there are overlapping versus divergent vulnerabilities.

\section{Consequences within the pandemic}

When disaggregated data is available, community outbreaks have been clearly shown to be clustered in lower income communities where ethnoracial minority groups reside-groups more likely to have precarious employment in lower paid essential fields, higher density living arrangements, as well as pre-existing chronic illness due to the effects of systemic forms of oppression. An intersectional lens sheds critical light on both the distribution of infection as well as the risks of worse outcomes for those infected. Economic precarity, intergenerational trauma, limited access to clean water or nutritious food, greater exposure to pollution are distributed along lines of social power and contribute to a priori illness burden. Systemic forms of discrimination often lead to delayed presentations to health services, limiting a person's access to high quality care even where universal healthcare is available. Morbidity and mortality due to COVID-19 infection increase with a range of underlying medical conditions, the risks for which are driven by social injustice in ways that are imbricated with individual biologies. When health care resource scarcity results from demand exceeding supply, triage protocols that rely on seemingly objective clinical criteria (e.g. age, underlying respiratory status, presence of underlying medical conditions) can inadvertently reinforce these structural forms of disadvantage, shaped by assumptions about health status, quality of life, and social utility (Carrieri et al. 2020; Scully 2020). Within the larger context of racialized health inequity, gender, economic disadvantage, age, and (dis)ability intersect in ways that lead to differential access to the supports that assist individuals in coping with the sequelae of the pandemic.

\section{An intersectional response}

Thinking about intersectionality can contribute to a more robust pandemic response, particularly when embraced within health and social policy. There have been calls, for instance, to ensure that COVID-19-related data (e.g. infection rates) is disaggregated. Failing to collect information about racialized or other relevant social groups obscures disproportionate impacts and contributes to what Charles Mills has called an epistemology of ignorance (Mills 2007). But, as has been abundantly clear from the pejorative usages and distortions of scientific data stemming from research on Indigenous communities in Canada, data cannot be collected and wielded without community involvement. As feminist science and technology studies (STS) scholars have emphasized, data pedagogies need to be re-imagined, and the issue of good relations and trust is central to data governance (Coleman 2020). Who has a voice at the table is a critical issue in policy discussions and decisions relating to how data will be collected and utilized. At a broader level, an intersectional response means supporting and promoting leaders from a range of national and community 
organizations as well as from local or regional First Nations, Inuit, and Metis governments, where their involvement as advisors, liaisons, or in governance roles is formalized and accountable. Non-tokenistic engagement entails that structurally disadvantaged communities are part of developing and implementing solutions-not prescribed them. Attending and responding to the intersections of race, gender, economic situation, disability, sexuality, and other axes of oppression meaningfully is crucial to the goals of equity and justice within the COVID-19 pandemic.

Funding None.

\section{Compliance with ethical standards}

Conflict of interest The authors declare that they have no conflict of interest.

\section{References}

Annamma, S. A. (2018). The pedagogy of pathologization: Dis/abled girls of colour in the school-prison nexus. New York: Routledge.

Carrieri, D., Peccatori, F. A., \& Boniolo, G. (2020). COVID-19: A plea to protect the older population. International Journal for Equity in Health., 19, 72. https://doi.org/10.1186/s12939-020-01193-5.

Cho, S., Crenshaw, K. W., \& McCall, L. (2013). Toward a field of intersectionality studies: Theory, applications, and praxis. Signs, 38(4), 785-810.

Coleman, B. (2020). Activating context: Disruptive data pedagogies and smart infrastructure. In Presentation at 4S/EASST conference, August 21, presented in the panel, teaching interdependent agency II: Feminist STS approaches to STEM pedagogy.

Crenshaw, K. W. (1991). Mapping the margins: Intersectionality, identity politics, and violence against women of color. Stanford Law Review, 43(6), 1241-1299.

Das Gupta, T. (2006). Racism/anti-racism, precarious employment and unions. In L. F. Vosko (Ed.), Precarious employ-ment: Understanding labour market insecurity in Canada (pp. 333-349). Montreal: McGill-Queen's University Press.

Estabrooks, C. A., \& Keefe, J. (2020). COVID-19 crisis in nursing homes is a gender crisis. Policy Options. https://policyoptions.irpp.org/magazines/may-2020/covid-19-crisis-in-nursing-homes-is-agender-crisis/. Accessed 16 June 2020.

Kajstura, A. (2019). Women's mass incarceration: The whole pie 2019. Prison Policy Initiative. https:// www.prisonpolicy.org/reports/pie2019women.html. Accessed June 17, 2020.

Laws, M. (2020). Why we capitalize 'Black' (and not 'white'). Columbia Journalism Review. June 16, 2020. https://www.cjr.org/analysis/capital-b-black-styleguide.php. Accessed September 22, 2020

Lewis, H. (2020). The coronavirus is a disaster for feminism. The Atlantic. 19 March 2020. https://www. theatlantic.com/international/archive/2020/03/feminism-womens-rights-coronavirus-covid19/60830 2/ Accessed 21 April 2020.

Lopez, K. (2018). "We are not a machine": Personal support workers' (ante)narratives of labour, leisure, and hope amidst politics of genderacialised care in long-term care homes. UWSpace. https://hdl. handle.net/10012/12850

Mein, S. (2020). COVID-19 and health disparities: The reality of 'the great equalizer.' Journal of General Internal Medicine, 14, 1-2.

Mills, C. (2007). White ignorance. In S. Sullivan \& N. Tuana (Eds.), Race and epistemologies of ignorance (pp. 11-38). New York: State University of New York Press.

Minello, A. (2020). The pandemic and the female academic. Nature World View. https://www.natur e.com/articles/d41586-020-01135-9 Accessed 19 April 2020.

Nellis, A. (2016). The colour of justice: Racial and ethnic disparity in state prisons. The Sentencing Project. https://www.sentencingproject.org/publications/color-of-justice-racial-and-ethnic-disparityin-state-prisons/. Accessed 17 June 2020. 
Power, K. (2020). The COVID-19 pandemic has increased the care burden of women and families. Sustainability: Science, Practice and Policy., 16(1), 67-73.

Scully, J. (2020). Disability, disablism, and COVID-19 pandemic triage. Journal of Bioethical Inquiry. https://doi.org/10.1007/s11673-020-10005-y

UN Policy Brief. (2020). The impact of COVID-19 on women. https://www.unwomen.org/-/media/headq uarters/attachments/sections/library/publications/2020/policy-brief-the-impact-of-covid-19-onwomen-en.pdf?la=en\&vs=1406. Accessed 19 April 2020.

Woods, C. (2012). (Im)mobile metaphors: Toward an intersectional rhetorical history. In K. Chavez \& C. Griffin (Eds.), Standing in the intersection: feminist voices, feminist practices in Communication Studies. Albany: SUNY Press.

Publisher's Note Springer Nature remains neutral with regard to jurisdictional claims in published maps and institutional affiliations. 